\title{
Fish oil and ischaemic heart disease
}

\author{
Steen Dalby Kristensen, Raffaele De Caterina, Erik Berg Schmidt, Stefan Endres
}

Fish oil products are available with or without prescription and are widely used by patients with ischaemic heart disease (IHD). The interest in fish oils, rich in the long chain n-3 polyunsaturated fatty acids (PUFA), eicosapentaenoic acid (n-3 20:5) and docosahexaenoic acid (n-3 22:6), originates primarily from the pioneering work of Dyerberg and Bang. ${ }^{1}$ Prompted by the low incidence of acute myocardial infarction in Eskimos in Greenland they suggested that a very high dietary intake of n-3 PUFA's from marine food offered protection against IHD. They showed that the Eskimos had a beneficial lipid pattern and that their balance between pro-aggregatory thromboxanes and anti-aggregatory prostacyclins was shifted towards an anti-thrombotic state compared with Danes. ${ }^{1}$ There is also evidence from Japan and Holland that dietary intake of fishprotects against IHD. $^{2}$ In the American MRFIT study the daily intake of n-3 PUFA was inversely related to IHD mortality in middle-aged men. ${ }^{3}$ However, no such relation was found in the American Physicians' Health Study. ${ }^{4}$

Experimental studies of atherogenesis and arterial thrombogenesis in various animal species lend some support to the hypothesis that dietary intake of n-3 PUFA's may play a part in primary or secondary prevention of IHD or both. ${ }^{5}$

University
Department of
Cardiology, Skejby
Hospital, Aarhus,
Denmark
S D Kristensen
CNR Institute of
Clinical Physiology,
University of Pisa,
Italy
R De Caterina
Department of
Medicine and
Haematology, Aalborg
Hospital, Aalborg,
Denmark
E B Schmidt
University
Department of
Medicine, Klinikum
Innenstadt, University
of Munich, Germany
S Endres
Correspondence to:
Dr S D Kristensen,
University Department of
Cardiology, Skejby Hospital,
DK-8200 Aarhus N,
Denmark.
Accepted for publication
28 April 1993

\section{n-3 PUFA: Pathophysiology and} influence on cardiovascular risk factors Dietary intake of fish or fish oil concentrates results in the incorporation of n-3 PUFAs into the membranes of human cells and gives rise to multiple actions on various biochemical factors or cellular events that may play a part in the development and progression of coronary atherosclerosis and its major complication, thrombosis. ${ }^{2}$ Fish oil supplementation in patients with IHD reduced plasma triglyceride, whereas the effect on total cholesterol, LDL cholesterol, and HDL cholesterol was unpredictable and usually slight. ${ }^{6}$ In some studies total cholesterol ${ }^{7}$ and LDL cholesterol $^{8}$ were even reported to increase. Theoretically, highly unsaturated fatty acids could enhance the risk of oxidative modification of LDL, but the results of studies of this important issue have been conflicting.

After the intake of n-3 PUFA platelet aggregability was inhibited and the bleeding time slightly prolonged, at least in part by a reduced production of bioactive thromboxane but probably also because of increased synthesis of prostacyclins. ${ }^{89}$ Studies in pigs indicated that $n-3$ PUFAs can stimulate the synthesis of endothelium-derived relaxing factor. ${ }^{10}$ This may contribute to the favourable change in the interaction between platelets and the vessel wall and may also be partly responsible for the reduction in blood pressure shown after dietary supplementation with n-3 PUFA in patients with mild hypertension. ${ }^{11} 12$ The risk of clinically significant episodes of bleeding is very low ${ }^{21}$ - probably lower than after a low dose of aspirin.

The synthetic activity of leucocytes is reduced after intake of fish oil mainly because the production of bioactive leukotrienes is decreased. ${ }^{14}$ Both synthesis of interleukin-1 and tumour necrosis factor by mononuclear cells $^{15}$ and of platelet-derived growth-factorlike protein by endothelial cells ${ }^{16}$ are inhibited after intake of n-3 PUFA. There is evidence that $n-3$ PUFAs reduce blood viscosity. ${ }^{17}$ Fish oil may impair fibrinolysis by increasing the plasma concentration of plasminogen activator inhibitor. This has also been shown for patients with $\mathrm{IHD}^{7}$ and is a potentially negative effect of fish oil supplements. The modulation of inflammatory responses could theoretically increase the risk of infection and cancer, but there are no clinical data to support this.

\section{Clinical studies in patients with} ischaemic heart disease

CHRONIC STABLE ANGINA PECTORIS

In an open study Saynor et al reported that patients with chronic stable angina pectoris given supplements of fish oil had a dramatic decrease in the number of angina attacks. ${ }^{18}$ This finding was not confirmed in a placebo controlled study in 36 patients. ${ }^{19}$ Other studies on small groups of patients were also negative: so at present there is no evidence that fish oil provides any symptomatic benefit in these patients.

\section{ACUTE MYOCARDIAL INFARCTION}

Burr et $a l^{20}$ investigated the effect of dietary advice to increase the intake of fatty fish (at least two fish meals per week or alternatively fish oil ( $0.9 \mathrm{~g}$ of $\mathrm{n}-3$ PUFA daily) for two years) in a randomised trial with a factorial design in 2033 men who recently had recovered from an acute myocardial infarction. There was a significant $29 \%$ reduction in the total number of deaths and in the number of deaths due to IHD in the group randomised 
Table 1 Randomised controlled trials on the effect of fish oil on the rate of restenosis after percutaneous coronary angioplasty (PTCA)

\begin{tabular}{lccccc}
\hline Study & $\begin{array}{l}\text { No of restenoses } \\
\text { Fish oil (\%) }\end{array}$ & $\begin{array}{l}\text { No of cases } \\
\text { Control (\%) }\end{array}$ & $\begin{array}{l}\text { Main } \\
\text { result }\end{array}$ & $n-3$ PUFA/day & $\begin{array}{l}\text { Treatment started } \\
\text { before PTCA? (days) }\end{array}$ \\
\hline Slack et al & $8 / 50(16)$ & $21 / 63(33)$ & + & $2 \cdot 7$ & No \\
Dehmer et al & $8 / 43(19)$ & $18 / 39(46)$ & + & $5 \cdot 4$ & Yes (7) \\
Grigg et al & $15 / 54(28)$ & $19 / 60(32)$ & 0 & $3 \cdot 0$ & No \\
Milner et al & $21 / 95(22)$ & $35 / 99(35)$ & + & $4 \cdot 5$ & No \\
Reis et al & $44 / 124(35)$ & $15 / 62(24)$ & 0 & $6 \cdot 0$ & Yes (1-7) \\
Nye et al & $5 / 36(14)$ & $18 / 71(25)$ & + & $3 \cdot 6$ & No \\
Bairati et al & $18 / 59(31)$ & $29 / 60(48)$ & + & $4 \cdot 5$ & Yes (21) \\
Kaul et al & $19 / 58(33)$ & $13 / 49(27)$ & 0 & $3 \cdot 0$ & Yes (1-7) \\
Total & $138 / 519(27 \%)$ & $168 / 503(33 \%)$ & & & \\
\hline
\end{tabular}

PUFA, polyunsaturated fatty acids. + = statistically significant reduction in restenosis rate in the fish oil group compared with the control group. $0=$ no statistical significant difference between the groups.

to a higher dietary intake of fatty fish. This difference was apparent after a few months. However, the number of non-fatal acute myocardial infarctions was higher in the group advised to eat fish. Therefore it seems unlikely, that the underlying protecting mechanism in this study was anti-thrombotic. Burr et al suggested that dietary fish oil may have an anti-arrhythmic effect. ${ }^{20}$ Indeed such an effect has been reported in animals ${ }^{21}$ and should be investigated in humans.

\section{RESTENOSIS AFTER PTCA}

About $25-40 \%$ of patients who undergo elective percutaneous transluminal coronary angioplasty (PTCA) develop restenosis within the first six months despite an initially succesful procedure. The effect of fish oil supplementation on the incidence of restenosis has been evaluated in eight controlled trials (table 1). ${ }^{22-29}$ In five of the trials the incidence of restenosis was reduced after fish oil supplementation 2223252728 whereas no such effect was found in three. 242629

Table 1 shows that the design of the studies varied in terms of the dose of n-3 PUFA. It seems logical to start treatment with $n-3$ PUFA at least one week before PTCA to ensure cellular incorporation of n-3 PUFAs by the time of the procedure. This was done in only two of the studies. ${ }^{2328}$ Some of the studies were hampered by the lack of angiographic end points. ${ }^{22} 252629$ In our opinion systematic angiography is mandatory, preferably six months after PTCA (or before when symptoms occur). Computer-assisted analysis of the degree of stenosis is preferable. Though the recent study by Bairati et al ${ }^{28}$ may be criticised because of a high exclusion rate of patients, it fulfils these criteria. In this study fish oil supplementation significantly reduced the incidence of restenosis. ${ }^{28}$ Furthermore, a dietary intake of $>0 \cdot 15 \mathrm{~g} /$ day n-3 PUFA was also associated with a lower frequency of restenosis. ${ }^{28}$ In the study by Nye et al supplementation with n-3 PUFA reduced the frequency of restenosis compared with placebo, but was not better than combination therapy with aspirin/dipyridamole. ${ }^{27}$ In some of the other studies all the patients were on permanent aspirin treatment. ${ }^{23} 2629$

In a recent meta-analysis of seven randomised trials ${ }^{22-28} \mathrm{O}^{\prime}$ Connor et al ${ }^{13}$ reported a significant reduction in the rate of restenosis in the patients treated with fish oil (odds ratio $=0.71 ; 95 \%$ confidence interval 0.54 to 0.94 ; $\mathrm{p}=0.016$ (two tailed)). O'Connor et al concluded that this was compatible with a small to moderate benefit of fish oil but that the result requires confirmation in a single randomised clinical trial with a large number of patients.

\section{CORONARY BYPASS SURGERY}

In a preliminary report on fish oil a daily dose of $4.5 \mathrm{~g} \mathrm{n}-3$ PUFA was compared with low dose aspirin. There was no difference in the frequency of late vein graft occlusion between the two groups. ${ }^{30}$

DOSE AND SOURCE OF $\mathrm{n}-3$ PUFA

In the studies in which fish oil supplements have been given to patients with IHD the daily dose of n-3 PUFA usually has been 2-7 g. Studies on the effect of fish oil on the rate of restenosis after PTCA do not suggest that the possible inhibition of restenosis was related to the dose of n-3 PUFA given. The exact dose of $n-3$ PUFA given in the DART study ${ }^{20}$ is not known, but on average the mean daily dose did not exceed $1 \mathrm{~g}$. Some of the potential beneficial biochemical and cellular effects of fish oil supplementation are dose dependent, ${ }^{2917}$ and at present the optimal daily dose of n-3 PUFA is unknown.

Fish oil supplementation and consumption of fish are different approaches. When a fish meal is eaten the amount of n-3 PUFA's varies with the type of fish eaten (table 2). The tendency to reduce the total saturated fat intake may also be important: fish often is eaten instead of food with a high content of saturated fat. If a fish oil concentrate is used it should not contain much vitamin A or D (to prevent hypervitaminosis); it should contain a high content of $n-3$ PUFA's and should be enriched with antioxidants.

\section{Conclusion}

Epidemiological studies suggest that dietary intake of fish protects against IHD. Intake of n-3 PUFAs has several beneficial effects on the biochemical factors and cellular functions involved in atherogenesis and thrombogenesis. The pathophysiology and clinical effects of fish oil should be studied further in patients with IHD. Large-scale trials are needed especially in patients with acute myocardial infarction and unstable angina pectoris but also in patients undergoing PTCA and coronary bypass surgery. 
1 Dyerberg J, Bang HO. Lipid metabolism, atherogenesis and haemostasis in Eskimos: the role of the prostaglandin-3 family. Haemostasis $1979 ; 8: 227-33$.

2 Leaf A, Veber PC. Cardiovascular effects of n-3 fatty acids. N Engl f Med 1988;318:549-57.

3 Dolecek TA, Grandits G. Dietary polyunsaturated fatty acids and mortality in the Multiple Risk Factor Intervention Trial (MRFIT). In: Simopoulus AP, Kife RR, Martin RE, Barlow SM, eds. Health effects of n-3 polyunsaturated fatty acids in sea food. World Rev Nutr Diet 1991;66:205-16.

4 Morris MC, Manson JE, Rosner B, Buring JE, Willet WC, Hennekens CH. A prospective study of fish consumption on cardiovascular disease [abstr]. Circulation 1992;86(suppl I):463.

5 Zhu B-Q Parmley WW. Modification of experimental and clinical atherosclerosis by dietary fish oil. Am Heart f 1990;119:168-78.

6 Harris WS. Fish oil and plasma lipids and lipoprotein metabolism in humans: a critical review. $f$ Lipid Res metabolism in hum

7 Schmidt EB, Kristensen SD, Dyerberg J. The effect of fish oil on lipids, coagulation and fibrinolysis in patients with angina pectoris. Artery 1988;15:316-29.

8 De Caterina R, Gianness D, Mazzone A, et al. Vascular prostacyclin is increased in patients ingesting $\omega-3$ polyunsaturated fatty acids before coronary artery bypass surgery. Circulation 1990;82:428-38.

9 Kristensen SD, Schmidt EB, Dyerberg J. Dietary supplementation with n-3 polyunsaturated fatty acids and human platelet function: a review with particula emphasis on implications for cardiovascular disease. f Int Med 1989;225(suppl 731):141-50.

10 Shimokawa H, Lam JYT, Chesebro JH, Bowie EJW, Vanhoutte PM. Effects of dietary supplementation with cod-liver oil on endothelium-dependent responses in porcine coronary arteries. Circulation 1987;76: in porcin

11 Knapp HR, FitzGerald GA. The antihypertensive effects of fish oil: A controlled study of polyunsaturated fatty acid supplements in essential hypertension. $N$ Engl 7 Med 1989:320:1037-43.

12 Bonaa KH, Bjerve KS, Straume B, Gram IT, Thelle D. Effect of eicosapentaenoic and docosahexaenoic acid on blood pressure in hypertension. N Engl f Med 1990; 322:795-80.

13 O'Connor GT, Malenka DJ, Olmstead EM, Johnson PS, Hennekens $\mathrm{CH}$. A meta-analysis of randomized trials of fish oil in the prevention of restenosis following coronary angioplasty. Am f Prev Med 1992;8:186-92.

14 Lee TH, Hoover RL, Williams JD, et al. Effect of dietary enrichment with eicosapentaenoic and docosahexaenoic acids on in vitro neutrophil and monocyte leukotriene generation and neutrophil function. $N$ Engl f Med 1985; 312:1217-24.

15 Endres S, Ghorbani $R$, Kelley VE, et al. The effect of dietary supplementation with $n-3$ polyunsaturated fatty acids on the synthesis of interleukin-1 and tumor necrosis factor by mononuclear cells. $N$ Engl f Med 1989; 320:265-71.

16 Fox PL, DiCorletto PE. Fish oils inhibits endothelial cell production of platelet-derived growth factor-like proPcience 1988;241:453-6.

17 Ernst E. Effects of n-3 fatty acids and blood rheology. f Int Med 1989;225(suppl 731):129-32.

18 Saynor $R$, Verel $D$, Gillott $T$. The long term effect of dietary supplementation with fish lipid concentrate on serum lipids, bleeding time, platelets and angina. Atherosclerosis 1984;50:3-10.

19 Kristensen SD, Schmidt EB, Andersen HR, Dyerberg J. Fish oil in angina pectoris. Atherosclerosis 1987;64:13-9.

20 Burr ML, Fehily AM, Gilbert JF, et al. Effects of changes in fat, fish, and fibre intakes on death and myocardial reinfarction: diet and reinfarction trial (DART). Lancet 1989;ii:757-61.

21 Charnock JS. Anti-arrhythmic effects of fish oils. World Rev Nutr Diet 1991;66:278-91.

22 Slack JD, Pinkerton CA, VanTassel J, et al. Can oral fish oil supplement minimize re-stenosis after percutaneous transluminal coronary angioplasty? [abstr]. $\mathfrak{f} \mathrm{Am} \mathrm{Coll}$ Cardiol 1987;9:64.

23 Dehmer GJ, Popma JJ, van den Berg EK, et al. Reduction in the early restenosis after coronary angioplasty by a diet supplemented with n-3 fatty acids. $N$ Engl $\mathcal{F}$ Med 1988;319:733-40.

24 Grigg LE, Kay TWH, Valentine PA, et al. Determinants of restenosis and lack of effect of dietary supplementation with eicosapentaenoic acid on the incidence of coronary artery restenosis after angioplasty. $\mathcal{f} \mathrm{Am}$ Coll Cardiol 1989;13:665-72.

25 Milner MR, Gallino RA, Leffingwell A, et al. Usefulness of fish oil supplements in preventing clinical evidence of restenosis after percutaneous coronary angioplasty. $\mathrm{Am}$ F Cardiol 1989;64:294-9.

26 Reis GJ, Boucher TM, Sipperly ME, et al. Randomised trial of fish oil for prevention of restenosis after coronary trial of fish oil for prevention of resten

27 Nye ER, Ilsley CDJ, Ablett MB, Sutherland W, Robertson MC. Effect of eicosapentaenoic acid on restenosis rate, clinical course and blood lipids in restenosis rate, clinical course and blood lipids in patients after percutaneous transluminal

28 Bairati I, Roy L, Meyer F. Double-blind randomized controlled trial of fish oil supplements in prevention of the recurrence of stenosis after coronary angioplasty. Circulation 1992;85:950-6.

29 Kaul U, Sanghvi S, Bahl KV, Dev V, Wasir HS. Fish oil supplements for prevention of restenosis after coronary angioplasty. Int f Cardiol 1992;35:87-93.

30 Roy L, Meyer F, Gingras L, Auger L. A double-blind randomized controlled study comparing the efficacy of fish oil and low dose ASA to prevent coronary saphenous vein graft obstruction after CABG [abstr]. Circulation 1991;84(suppl. II):285. 